\title{
Suitable Environmental Flow Release Criteria for Both Human and Riverine Ecosystems: Accounting for the Uncertainty of Flows
}

\author{
Jian Tang, Xinan Yin, ChunXue Yu, and Zhifeng Yang \\ State Key Laboratory of Water Environment Simulation, School of Environment, \\ Beijing Normal University, Beijing 100875, China \\ Correspondence should be addressed to Xinan Yin, yinxinan@163.com \\ and Zhifeng Yang, zfyang@bnu.edu.cn \\ Received 16 November 2012; Accepted 11 December 2012 \\ Academic Editor: Yongping Li
}

Copyright (C) 2012 Jian Tang et al. This is an open access article distributed under the Creative Commons Attribution License, which permits unrestricted use, distribution, and reproduction in any medium, provided the original work is properly cited.

\begin{abstract}
Environmental flow (e-flow) release criteria are key parameters in water resources management and riverine ecosystem protection. The previous methods for e-flow criterion determination are based on the historical flow time series without the consideration of flow uncertainty. Due to low possibility of reoccurrence of the historical flows and the uncertainty of future flows, the flow uncertainty needs to be integrated in the process of determining e-flow release criteria. In this research, a new method is proposed to determine the optimal e-flow release criteria under flow uncertainty accounting for both the human and riverine ecosystem needs. In the new method, the scenario tree method is applied to generate the scenarios of flows, which can cover most of possible flow conditions and can effectively reflect the uncertainty of flows; the Range of Variability Approach (RVA), a most commonly used method to assess the flow regime alteration, is refined by incorporating the uncertainty of flows. The Tang River in Northern China is taken as a case study to test the effectiveness of the new method. The results show that the previous method obviously overestimates the optimal e-flow release criteria and the new method can get more suitable criteria that are suitable for both human and riverine ecosystems.
\end{abstract}

\section{Introduction}

One-third of the world's population are under the pressure of water scarcity and estimates suggest that by 2050 more countries will experience water shortage [1]. Increasing water supply has become an urgent task in the world $[2,3]$. Rivers as the major sources for water supply are expected to provide more water to humans. However, rivers also need water to sustain their health $[4,5]$. The overwithdrawal of water from rivers has led to severe 
degradation of riverine ecosystems in the world [6-8]. To address the conflict between human and riverine ecosystems, it is necessary to conduct research on how to balance the water requirements between the two users [9-12].

The concept of environmental flows (e-flows) is developed to direct water allocation between humans and rivers. Sustaining e-flows has become a basic principle for water resources management [1, 5, 13-15]. E-flows are defined as the volume of water that should remain in a river and its variation over time to sustain specified ecosystem conditions [16]. Many methods have been developed to determine the e-flows, such as hydrological methods, hydraulic rating methods, habitat simulation methods, and holistic methods [17-22]. Among them, many methods try to determine one or several fixed values of e-flows [20, 21]. After the development of several decades, scientists found that the full range of natural intra- and interannual variability of hydrological regimes, and the associated characteristics of flow magnitude, frequency, duration, timing, and rate of change, are critical in determining the structures and functions of riverine ecosystems [17, 23, 24]. It is widely acknowledged that e-flow provision should try to maintain natural flow regimes rather than only to ensure one or several fixed values [25-27]. Thus, the reduction of natural flow regime alteration has become the key principle for e-flow assessment and provision. This principle has contributed to the implementation of e-flow management on thousands of rivers worldwide $[22,28]$.

The e-flows reflect the characteristics of riverine ecosystems. In real-world water resources management and e-flow provision, the e-flows must be balanced with the water requirements of humans $[11,12]$. Thus, after determining the e-flow requirements, the e-flow release criteria need to be further determined. The release criteria directly specify the volume of water used for e-flow provision. The e-flow release criteria can be equal to, greater than or less than the e-flow requirements. They need to be determined accounting for both the human and riverine ecosystem needs. Much research has been done to determine the e-flow release criteria to downstream rivers. Most of the research only tried to maintain the minimum eflows and regarded the difference between the mean annual flows and the minimum e-flows as the planned water diversion to humans [20,29]. These methods are easy to apply in realworld water resources management, but they have not taken into account the maintenance of natural flow regimes. To effectively account for natural flow regimes, Shiau and $\mathrm{Wu}$ applied the Range of Variability Approach (RVA) to investigate the effect of e-flow release criteria on restoring the natural flow regime downstream and evaluated the tradeoffs between the ecosystem and human needs associated with various combinations of water withdrawal and e-flow release criteria [30]. Further, they used a compromise programming methodology to identify the optimal e-flow release criteria that simultaneously assured the water supply reliability and sustained the natural flow variability [31]. The innovative research is useful to balance e-flow release and water diversion. In the research, the historical flow time series were used to calibrate the e-flow release and water diversion models and got the optimal values for e-flow release criteria. When the optimized values are used to direct water resources management in the future, the underlying assumption is that the historical flow time series will occur again in the future. In fact, the flows in the future are quite uncertain $[32,33]$, and the reoccurrence possibility of the historical flows is very low [34-39]. Thus, the values optimized based on historical flows may be not optimal for the future flow conditions [40,41]. In addition, uncertainty is a basic characteristic of flows. The use of historical flow data for e-flow release criteria determination neglects the uncertainty of flows [42]. It is necessary to establish new methods to optimize e-flow release criteria accounting for flow uncertainty.

Shiau and $\mathrm{Wu}$ 's research was performed for the rivers regulated by weirs. It is just a simple scenario in e-flow release criterion determination, but it can serve as a significant 
foundation for future research on more complex river conditions with cascade dams. In this research, we also consider this basic scenario and extend the previous research by accounting for flow uncertainty. To incorporate the uncertainty of flows into the process of e-flow criterion determination, in the method section the scenario tree method is applied to generate flow scenarios that can effectively cover the possible conditions of flows. The RVA is refined to suit the uncertainty of flows and is used to measure the degree of flow regime alteration. The metric for water supply reliability is also refined due to the flow uncertainty. In the case study section, the Tang River in Northern China is applied to test the effectiveness of the new method.

\section{Method}

\subsection{Scenario Tree}

Scenario tree approach is a commonly used method to generate the possible scenarios of flows. It is effective to realize the twin goals of covering the possible scenarios of flows and reducing the computing time for optimizing water resources management parameters by combining and reducing similar flow scenarios. It is widely used in water resources management, and is also adopted in this research [43-46].

A scenario tree may be represented by a finite set of nodes. It starts from the root node at the first period and eventually branches into nodes at the next period. Each node has a unique predecessor node, but possibly several successors. The branching continues up to nodes at the final period whose number corresponds to the number of scenarios. Each possible discrete outcome is called a scenario. The generated set of scenarios, with the corresponding probabilities, can be viewed as a representation of the underlying probability distribution [47].

Constructing the scenario tree involves two steps, that is, scenario generation and scenario reduction. In the step of scenario generation, a scenario tree is firstly generated which can represent sufficiently well the historical data. Sampling from historical time series or from statistical models is the most popular method for generating scenarios. The resulting tree may be much larger than the desired size, because too many scenarios may lead to a dimensionality problem. So in the step of scenario reduction, the number of scenarios is reduced to reach the size limit that is still a sufficient good approximation of the original one [44]. The reduction algorithms based on Kantorovich distance not only consider distances, but also the probabilities of the scenarios, in order to avoid the important information might be lost. Scenarios are deleted if the Kantorovich distance near to some other scenario. In each step one scenario is deleted and the probability of the deleted scenario is added to the nearest scenarios. This deleting procedure is applied iteratively, until a given number of scenarios is remaining. The details for scenario generation and reduction can refer to Brand et al. [48].

Based on the scenario tree approach, a specified number of scenarios of flows can be generated. In this research, one scenario is the daily flows for one year. The sum of all probabilities of the remaining scenarios should remain equal to 1 .

\subsection{Refined RVA under Flow Uncertainty}

The RVA is the most commonly used method to assess the degree of flow regime alteration. In RVA, 32 Indicators of Hydrological Alteration (IHAs) are adopted (Table 1). These IHAs are 
divided into five groups, that is, magnitude, duration, timing, frequency, and rate of change [17]. According to the RVA, a range of variation for each IHA is derived from the natural hydrological time series and is set as the flow management target. The range of the 25th and 75th percentiles of the natural daily flows has been recommended as the management target [18]. The degree of alteration, $D_{m}$, is used to measure the deviation of the impacted flow regime from the natural one for the $m$ th hydrological indicator, which is defined by

$$
D_{m}=\left|\frac{N_{o, m}-N_{e, m}}{N_{e, m}}\right| \times 100 \%,
$$

where $N_{o, m}$ is the observed number of postimpact years in which the value of the $m$ th hydrological indicator falls within its RVA target range; $N_{e, m}$ is the expected number of postimpact years in which the indicator value falls within the RVA target range.

Equation (2.1) is from the original RVA, which does not account for the possibility of the flow time series in each year. To take into account the possibility of flows of each year, (2.1) could be replaced by the following equation:

$$
D_{m}=\left|\frac{N_{o, m} / N_{m}-N_{e, m} / N_{m}}{N_{e, m} / N_{m}}\right| \times 100 \%=\left|\frac{p_{o, m}-50 \%}{50 \%}\right| \times 100 \%
$$

where $N_{m}$ is the observed number of post-impact years; $p_{o, m}$ is the possibility of post-impact years in which the value of the $m$ th hydrological indicator falls within its RVA target range. $N_{e, m} / N_{m}$ is replaced by $50 \%$, because the expected possibility of post-impact years in which the value of the $m$ th hydrological indicator falls within 25th and 75th percentile is equal to $50 \%$.

Equation (2.2) could be further replaced by (2.3) by incorporating the possibility of the flow time series in each year

$$
D_{m}=\left|\frac{\sum p_{i, m}-50 \%}{50 \%}\right| \times 100 \%
$$

where $p_{i, m}$ is the possibility of the $i$ th flow scenario under which the value of the $m$ th hydrological indicator falls within its RVA target range. $\sum p_{i, m}$ is not equal to 1 in this formula, because the indicator values of only a few post-impacted flow scenarios can fall within 25th and 75 th percentiles.

Then, the overall degree of hydrologic alteration $\left(D_{o}\right)$ is defined as follows:

$$
D_{o}=\frac{1}{32} \sum_{m=1}^{32} D_{m} .
$$

The degree of flow regime alteration could be further categorized into three levels: low alterations (values of $D$ between 0 and 0.33), moderate alterations (values of $D$ between 0.33 and 0.67 ), and high alterations (values of $D$ between 0.67 and 1.0) [49]. 
Table 1: Hydrological alterations corresponding to the optimal e-flow release criterion under flow uncertainty.

\begin{tabular}{lcc}
\hline IHA group & IHA & Values \\
\hline & Mean flow in January & 1 \\
& Mean flow in February & 1 \\
& Mean flow in April & 1 \\
& Mean flow in May & 1 \\
Group 1: magnitude of & Mean flow in June & 1 \\
monthly flow conditions & Mean flow in July & 1 \\
& Mean flow in August & 0.71 \\
& Mean flow in September & 0.68 \\
& Mean flow in October & 0.82 \\
& Mean flow in November & 1 \\
& Mean flow in December & 1 \\
& Annual 1-day minimum flow & 1 \\
\hline Group 2: magnitude and & Annual 1-day maximum flow & 0.11 \\
duration of annual extreme & Annual 3-day minimum flow & 0.22 \\
flow conditions and base flow & Annual 3-day maximum flow & 0.17 \\
condition & Annual 7-day minimum flow & 0 \\
& Annual 7-day maximum flow & 0.02 \\
& Annual 30-day minimum flow & 0.56 \\
pulses & Annual 30-day maximum flow & 0.11 \\
Group 5: rate and frequency of & Mean of all positive differences between consecutive daily flows & 0.45 \\
flow condition changes & Annual 90-day minimum flow & 0.84 \\
& Annual 90-day maximum flow & 1 \\
Group 4: frequency and & Meand negative differences between consecutive daily flows & 0.45 \\
duration of high and low & Number of flow reversals & 1 \\
\hline Group 3: timing of annual & Number of low pulses in each year & 1 \\
\hline & D-day minimum flow divided by mean flow in each year & 0.78 \\
\hline
\end{tabular}

\subsection{Refined Metric for Water Supply Reliability}

The water supply reliability is defined as the ratio of the overall actual water supply to humans and the overall planned water supply over a planned period [11]. Equation (2.5) is the previous metric for water supply reliability, which does not account for the flow uncertainty

$$
R=\frac{\sum_{j=1}^{T} \sum_{i=1}^{365} R W_{i j}}{\sum_{j=1}^{T} \sum_{i=1}^{365} P W_{i j}}
$$


where $R$ is the water supply reliability; $T$ is the number of years during the planned water supply period; $R W_{i j}$ is the actual water supply to humans for the $i$ th day $j$ th year; $P W_{i j}$ is the planned water supply to humans for the $i$ th day $j$ th year.

Based on (2.5), we could further develop the metric for water supply reliability accounting for the possibility of flow scenarios (see (2.6)). Here, we assume the planned water supply for each year is the same. In fact, many cases of real-world water supplies meet this assumption during a planned horizon $[4,11]$

$$
R=\frac{\sum_{j=1}^{T} \sum_{i=1}^{365} R W_{i j}}{T \sum_{i=1}^{365} P W_{i j}}=\frac{\sum_{j=1}^{T} R_{j}}{T}=\sum_{k=1}^{N} p_{k} \times R_{k}
$$

where $R_{j}$ is the water supply reliability for year $j ; N$ is the scenario number after scenario reduction; $R_{k}$ is the water supply reliability for flow scenario $k$; $p_{k}$ is the possibility of flow scenario $k$.

\subsection{Water Diversion Model}

In this research, we consider the rivers regulated by weirs. The priority-based weir management model is suitable for water diversion management [4]. We adopt the water diversion model by Shiau and $\mathrm{Wu}[30,31,50,51]$ for e-flow release and water diversion. The model is as follows:

$$
\begin{aligned}
& \text { If } Q_{N, k}<Q_{\mathrm{IF}} \text {, then } Q_{E, k}=Q_{N, k} \text {, and } R Q_{U, k}=0, \\
& \text { If } Q_{\mathrm{IF}} \leq Q_{N, k}<D_{U, k}+Q_{\mathrm{IF}} \text {, then } Q_{E, k}=Q_{\mathrm{IF}} \text {, and } R Q_{U, k}=Q_{N, k}-Q_{\mathrm{IF}}, \\
& \text { If } Q_{N, k} \geq D_{U, k}+Q_{\mathrm{IF}} \text {, then } Q_{E, k}=Q_{N, k}-D_{U, k} \text {, and } R Q_{U, k}=D_{U, k},
\end{aligned}
$$

where $Q_{N, k}$ is the inflow to the diversion on day $k$; $Q_{\mathrm{IF}}$ is the e-flow release criterion, which is employed to meet environmental flow requirement, and this parameter will be optimized in this paper; $Q_{E, k}$ is the actual flow released to the downstream river on day $k ; D_{U, k}$ is the planned water supply to human beings on day $k ; R Q_{U, k}$ is the actual water supply to human beings on day $k$.

\subsection{Objective of E-Flow Release Criterion Optimization}

Increasing water supply reliability and reducing the degree of flow regime alteration are the two conflicting objectives for water resources management. It is a typical multiobjective optimization. To find the optimal e-flow release criteria, it is necessary to integrate the two objectives into one objective. Based on the method of compromise programming [42, 51-53], the combined objective is as follows:

$$
\operatorname{Min}\left[w_{D}\left(\frac{D_{o}-D_{o, \min }}{D_{o, \max }-D_{o, \min }}\right)^{2}+w_{R}\left(\frac{R_{\max }-R}{R_{\max }-R_{\min }}\right)^{2}\right]^{1 / 2}
$$


where $D_{o, \max }$ and $D_{o \text {,min }}$ are the maximum and minimum values of the overall degree of hydrological alteration. $R_{\max }$ and $R_{\min }$ are the maximum and minimum values of water supply reliability. $W_{D}$ and $W_{R}$ are weighting factors for hydrological alteration and water supply reliability, respectively. As an example, in this research they are set at 0.5 , indicating an equal position for human and riverine ecosystems.

\section{Case Study}

The Tang River is an important river in northern China. It is about $123 \mathrm{~km}$ long, with a drainage area of $1462 \mathrm{~km}^{2}$. The river is mainly used for water supply. It provides water for four major water users: the Liaoning Chemical Industry Group, the Anshan Domestic Water Supply Company, the Liaoyang Domestic Water Supply Company, and the Gongchangling Mine Industry Company. The current planned water supplies for these users are $54.8 \times 10^{6}$, $73 \times 10^{6}, 36.5 \times 10^{6}$, and $18.3 \times 10^{6} \mathrm{~m}^{3}$ each year, respectively. It is the main drinking water source of Liaoyang City. Due the diversion of large amount of water for the river, severe degradation has occurred in the river ecosystem. It is urgent to balance the water requirements of human beings and rivers. To demonstrate the methods established above, we assume all the planned water supplies are withdrawn from a weir on the river. The daily runoff data from 1950 to 1969 at the Tanghe gauge station are used in this paper.

\section{Results}

Based on the historical runoff data, the scenario tree approach is applied to generate the possible scenarios of flows. 2000 scenarios of flows are generated and are then reduced to 200 scenarios. In this research, the e-flow release criterion $Q_{\mathrm{IF}}$ is assumed to be constant for each month. The optimal value for $Q_{\mathrm{IF}}$ is determined by exploring all the values of $Q_{\mathrm{IF}}$ between $0 \mathrm{~m}^{3} / \mathrm{s}$ and the $5.8 \mathrm{~m}^{3} / \mathrm{s}$ (the mean annual flow) with an increment of $0.1 \mathrm{~m}^{3} / \mathrm{s}$ and evaluating the effects of different $Q_{\mathrm{IF}}$ on the hydrological alterations and water supply reliability. Under the present water supply of $5.8 \mathrm{~m}^{3} / \mathrm{s}$, the minimum and maximum water supply reliabilities are 0.2 and 0.58 , and the minimum and maximum degrees of flow regime alteration are 0.48 and 0.81 , respectively. According to (2.8), the optimal e-flow release criterion is $1.2 \mathrm{~m}^{3} / \mathrm{s}$. The corresponding overall hydrological alteration and water supply reliability are 0.58 and 0.47 , respectively. The very low reliability of water supply is due to the high planned water supply (approaching to the mean annual water supply) and the inability of weir to store water. The flow alteration degrees for the 32 IHAs are listed in Table 1.

\section{Hydrological Alterations of Indicators in Group 1}

The alteration degrees for the indicators related to monthly magnitude are all in the category of high alteration. It is due to the high planned water supply to humans. The ecological functions closely related to the monthly flows, such as the provision of habitat in river channels, will be severely disturbed. Interestingly, the alteration degrees for the monthly flows in July, August, and September are relatively lower. It is because the three months are in the flood season and many high flows could be released following the present water diversion and e-flow release model during these three months. 


\section{Hydrological Alterations of Indicators in Group 2}

The alteration degrees for 1-, 3-, 7-, and 30-day minimum flows and the 1-, 3-, and 7-day maximum flows are all in the category of low alterations. It indicates the ecological functions related to extreme flow magnitude could be effectively maintained. The other indicators are in the category of moderate or high alterations because these indicators are similar to the monthly flows that are significantly influenced by the high planned yield.

\section{Hydrological Alterations of Indicators in Group 3}

The alteration degrees for the date of extreme flows are all in the categories of low flows. The timing of annual extremes significantly influence the start of life cycle of aquatic organisms. Maintaining the timing of annual extremes are possibly more important than the maintenance of the magnitude of annual extreme in terms of the life cycle of aquatic organisms $[25,54]$.

\section{Hydrological Alterations of Indicators in Group 4}

The alterations degrees for the indicators of frequency and duration of high and low pulses are all in the category of low alteration. The low alteration of these indicators is significant to sustain the ecological functions related to the high flow pulses such as the provision of access by fish to floodplains for feeding, spawning, and nursery areas and the determination of the streambed substrate size, and the functions related to extreme low flows such as the elimination of exotic species.

\section{Hydrological Alterations of Indicators in Group 5}

The indicators related to the rate of flow changes and flow reversals are in moderate or high degree. It mainly stems from the reduction of flow reversal when the flows are between the e-flow release criteria and the sum of the release criteria and the planned yield.

\section{Discussion}

\subsection{Comparison of the Optimal Results with and without Considering the Flow Uncertainty}

In the above section, the planned water supply is $5.8 \mathrm{~m}^{3} / \mathrm{s}$. We further set the planned yield between $1 \mathrm{~m}^{3} / \mathrm{s}$ and $6 \mathrm{~m}^{3} / \mathrm{s}$ with an increment of $1 \mathrm{~m}^{3} / \mathrm{s}$. Under these planned yields, the optimal e-flow criteria and the corresponding degree of flow regime alteration and water supply reliability are determined with and without accounting for flow uncertainty, respectively. The results are shown in Table 2.

Table 2 shows the optimal e-flow criteria under flow uncertainty are obviously lower than those without taking into account the flow uncertainty. Thus, without taking into account the flow uncertainty, the water resources managers tend to sustain more water in the river ecosystems. The obvious difference of e-flow criteria under the two conditions further demonstrates the needs of considering flow uncertainty. The degrees of flow regime alteration under the flow uncertainty will be in the category of moderate alteration, while the alteration degrees without considering the flow uncertainty are all in the category of low alteration. The higher alteration degree stems from the lower e-flow release criteria. It indicates that 
Table 2: The optimal results for different planned water supplies.

\begin{tabular}{lcccccc}
\hline Planned water & \multicolumn{3}{c}{ Flow uncertainty } & \multicolumn{3}{c}{ Historical data } \\
supply $\left(\mathrm{m}^{3} / \mathrm{s}\right)$ & $\begin{array}{c}\text { E-flow release } \\
\text { criterion } \\
\left(\mathrm{m}^{3} / \mathrm{s}\right)\end{array}$ & $\begin{array}{c}\text { Hydrological } \\
\text { alteration }\end{array}$ & $\begin{array}{c}\text { Water supply } \\
\text { reliability }\end{array}$ & $\begin{array}{c}\text { E-flow release } \\
\text { criterion } \\
\left(\mathrm{m}^{3} / \mathrm{s}\right)\end{array}$ & $\begin{array}{c}\text { Hydrological } \\
\text { alteration }\end{array}$ & $\begin{array}{c}\text { Water supply } \\
\text { reliability }\end{array}$ \\
\hline 1 & 1.2 & 0.37 & 0.69 & 4.4 & 0.11 & 0.65 \\
2 & 1 & 0.49 & 0.66 & 3.2 & 0.12 & 0.70 \\
3 & 1 & 0.52 & 0.60 & 3.4 & 0.15 & 0.65 \\
4 & 1.2 & 0.52 & 0.54 & 3.9 & 0.19 & 0.58 \\
5 & 1.2 & 0.54 & 0.50 & 3.7 & 0.22 & 0.56 \\
6 & 1.8 & 0.54 & 0.41 & 4.1 & 0.22 & 0.51 \\
\hline
\end{tabular}

without taking into account the flow uncertainty the optimized e-flow criteria will be positive to the maintenance of natural flow regime and consequently the better protection of riverine ecosystems. The water supply reliabilities under the two scenarios generally do not show obvious difference. It indicates the major influence of incorporating flow uncertainty is on e-flow release criteria and the corresponding degree of flow regime alteration, while the influence on human water supply is very limited.

Because it is too tedious to compare the difference of alteration degree for each of the 32 IHAs between the uncertain and certain flows, we compare the difference for the average values for the five groups. The results are shown in Figure 1. Under inflow uncertainty, the alteration degree for the magnitude of monthly flows (group 1), magnitude and duration of annual extreme flows (group 2), timing of annual extreme flow conditions (group 3) and rate and frequency of flow condition changes (group 5) are always greater than that under the certain flows (the historical data), while only the frequency and duration of high and low pulses (group 4) show lower alteration degrees for some planned yields.

\subsection{Effects of Changing Both E-Flow Release Criteria and Planned Yields}

Besides the optimal e-flow criteria which have been discussed above, the water resources managers are also interested in the effects of different combination of e-flow criteria and planned yields on water supply reliability and flow regime alteration. Here, we further determine the water supply reliability and flow regime alteration under different combination of e-flow criteria and planned yields. Both the planned water supply and the e-flow release criteria vary from 0 to $6.3 \mathrm{~m}^{3} / \mathrm{s}$ (average runoff from 1950 to 1969 at Tanghe gauge station) with an increment of $0.1 \mathrm{~m}^{3} / \mathrm{s}$, which forms 4096 e-flow criteria and water diversion scenarios.

Figure 2 shows the water supply reliability under various combinations of e-flow release criteria and planned water diversion. Higher water supply reliability mainly locates in the lower left corner of the contour map, that is, low e-flow release criteria and low planned water supply. Despite the high water supply reliability, these combinations of e-flow and water supply are not recommended due to the low volume of the total water supply. Lower water supply reliability appears in the upper right corner of the contour map, that is, high e-flow release criteria and high planned water supply. Besides, the distance between two contour curves decreases with the increase of the reliability. It indicates that under the high 


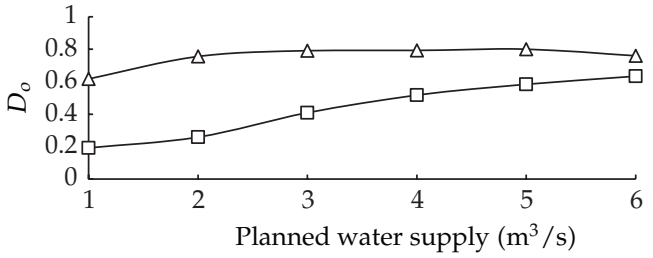

$\rightarrow-$ Historical data

$\triangle$ Flow uncertainty

(a)

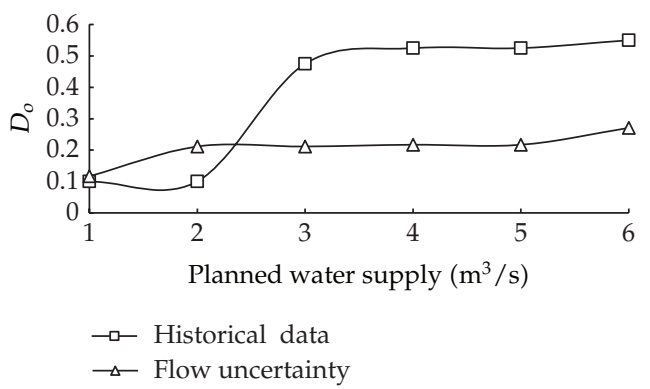

(c)

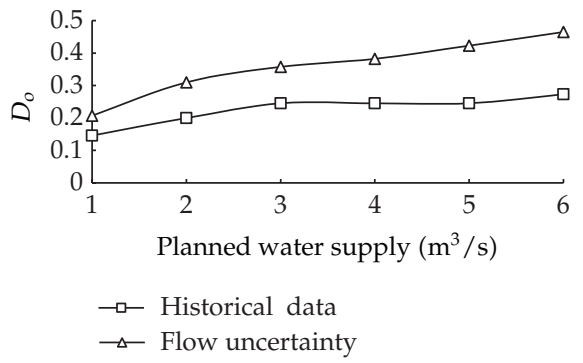

(b)

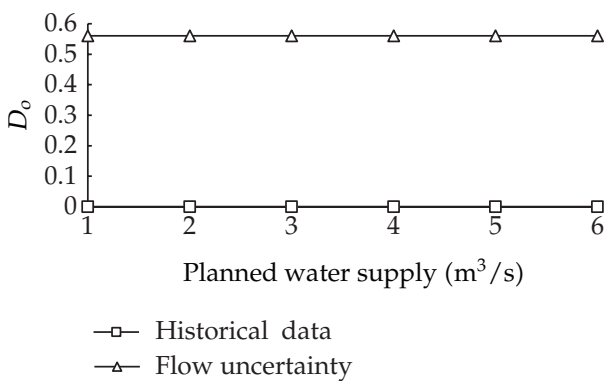

(d)

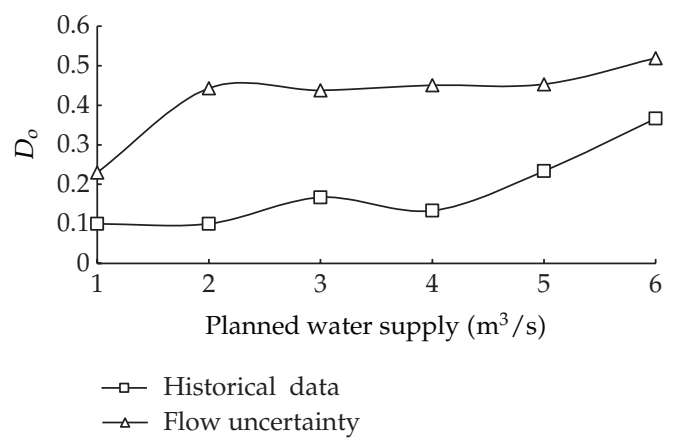

(e)

Figure 1: The average hydrological alteration degree of each group of IHAs with and without the consideration of flow uncertainty. (a) group 1; (b) group 2; (c) group 3; (d) group 4; (e) group 5.

water supply reliability the reliability is more sensitive to the change of e-flow criteria and planned water supply than that under low reliability.

Figure 3 shows the overall hydrological alteration for different e-flow criteria and planned water supply. When the planned water supply is no more than $2.8 \mathrm{~m}^{3} / \mathrm{s}$, the degree of flow regime alteration will be always in the category of low alteration (less than 0.33 ). From the perspective of riverine ecosystem protection, it is recommended to set the planned water supply no more than $2.8 \mathrm{~m}^{3} / \mathrm{s}$. In addition, when the e-flow release criterion is less than $1 \mathrm{~m}^{3} / \mathrm{s}$ and the planned water supply is greater than $1.3 \mathrm{~m}^{3} / \mathrm{s}$, the degree of flow regime alteration is always in the category of high alterations. The e-flow release and water supply combination within this region should be avoided to protect the riverine ecosystem. Thus, although the planned water supply and e-flow release criteria can influence the degree of flow regime alteration simultaneously, the low and high alteration degree is corresponding to 


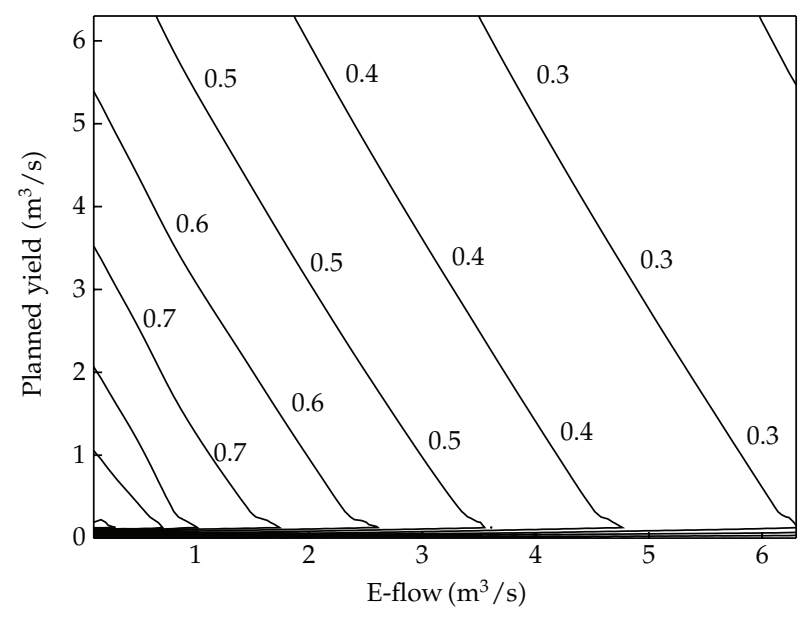

Figure 2: Contour map of the water supply reliabilities under different e-flow release criteria and planned yields.

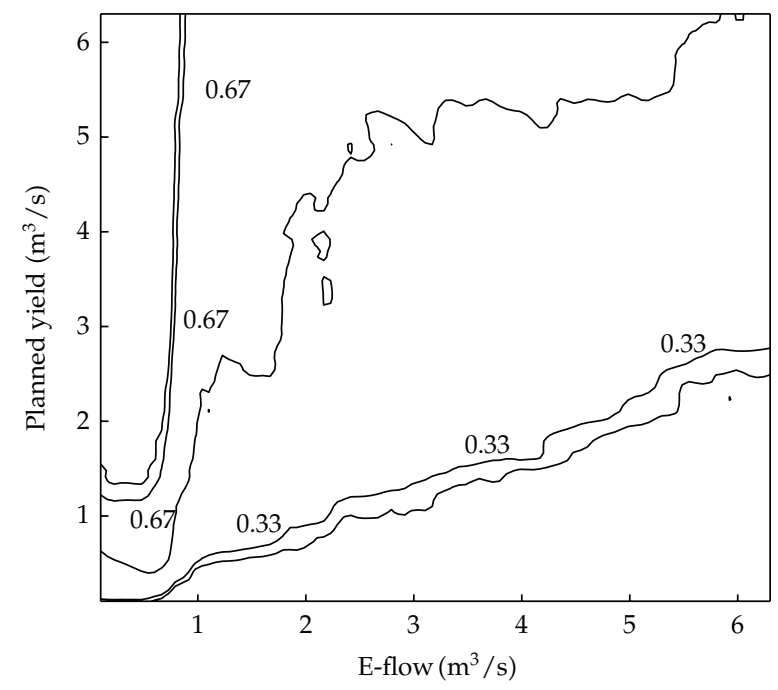

Figure 3: Contour map of the degree of flow regime alteration under different e-flow release criteria and planned yields.

limited ranges of e-flow release criteria and planned water supply. The identified ranges are helpful for the water resources managers to design suitable combinations of planned water supply and e-flow release criteria.

\section{Conclusions}

In this study, a method is developed to determine the optimal e-flow release criteria accounting for the uncertainty of flows. The scenario tree method is applied to generate the scenarios of flows and to reduce the flow scenarios to specified number of scenarios. The reduced scenarios can sufficiently cover the possible flow conditions and can effectively 
reflect the uncertainty of flows. The RVA, a widely used method to assess the flow regime alteration, is refined by incorporating the uncertainty of flows. The metric for water supply reliability is also modified through the incorporation of the possibility of each flow scenarios. The new method is applied to the Tang River to demonstrate its effectiveness. The following conclusions are drawn.

(i) The previous method for e-flow criteria determination is based on the historical flow time series without the consideration of flow uncertainty. The case study shows the previous method obviously overestimates the optimal e-flow release criteria suitable for both humans and ecosystems. Because the historical flow time series will not occur again and the future flows are still uncertain, the flow uncertainty needs be integrated in the process of e-flow release criteria.

(ii) Although the planned water supply and e-flow release criteria can influence the degree of flow regime alteration simultaneously, the low and high alteration degree may be corresponding to limited ranges of e-flow release criteria and planned water supply. For example, in this research, the low degree of the overall flow regime alteration is mainly corresponding to the planned yield no more than $2.8 \mathrm{~m}^{3} / \mathrm{s}$, while the high alteration degree is mainly corresponding to the e-flow release criteria less than $1 \mathrm{~m}^{3} / \mathrm{s}$. The identified ranges can help the water resources managers design suitable combinations of planned water supply and e-flow release criteria.

\section{Acknowledgments}

The authors thank the International Science and Technology Cooperation Program of China (no. 2011DFA72420), the National Science Foundation for Innovative Research Group (no. 51121003), and National Natural Science Foundation of China (no. 50939001) for their financial support.

\section{References}

[1] G. E. Petts, "Instream flow science for sustainable river management," Journal of the American Water Resources Association, vol. 45, no. 5, pp. 1071-1086, 2009.

[2] R. A. Wurbs, "Modeling river/reservoir system management, water allocation, and supply reliability," Journal of Hydrology, vol. 300, no. 1-4, pp. 100-113, 2005.

[3] B. Rajagopalan, K. Nowak, J. Prairie et al., "Water supply risk on the Colorado River: can management mitigate?" Water Resources Research, vol. 45, no. 8, Article ID W08201, 2009.

[4] X. A. Yin and Z. F. Yang, "Development of a coupled reservoir operation and water diversion model: balancing human and environmental flow requirements," Ecological Modelling, vol. 222, no. 2, pp. 224-231, 2011.

[5] S. K. Jain, "Assessment of environmental flow requirements," Hydrological Processes, vol. 26, no. 22, pp. 3472-3476, 2012.

[6] M. A. Palmer, C. A. Reidy Liermann, C. Nilsson et al., "Climate change and the world's river basins: anticipating management options," Frontiers in Ecology and the Environment, vol. 6, no. 2, pp. 81-89, 2008.

[7] P. B. McIntyre, S. Glidden, S. E. Bunn, C. A. Sullivan, C. R. Liermann, and P. M. Davies, “Global threats to human water security and river biodiversity," Nature, vol. 467, no. 7315, pp. 555-561, 2010.

[8] K. H. Bowmer, "Water resource protection in Australia: links between land use and river health with a focus on stubble farming systems," Journal of Hydrology, vol. 403, no. 1-2, pp. 176-185, 2011.

[9] R. M. Vogel, J. Sieber, S. A. Archfield, M. P. Smith, C. D. Apse, and A. Huber-Lee, "Relations among storage, yield, and instream flow," Water Resources Research, vol. 43, no. 5, Article ID W05403, 2007. 
[10] Z. F. Yang, T. Sun, B. S. Cui, B. Chen, and G. Q. Chen, "Environmental flow requirements for integrated water resources allocation in the Yellow River Basin, China," Communications in Nonlinear Science and Numerical Simulation, vol. 14, no. 5, pp. 2469-2481, 2009.

[11] X.-A. Yin, Z.-F. Yang, and G. E. Petts, "Reservoir operating rules to sustain environmental flows in regulated rivers," Water Resources Research, vol. 47, no. 8, Article ID 7206, 2011.

[12] N.-S. Hsu, C.-H. Chiang, W.-M. Cheng, and C.-C. Wei, "Study on the trade-off between ecological base flow and optimized water supply," Water Resources Management, vol. 26, no. 11, pp. 3095-3112, 2012.

[13] M. R. Su, Z. F. Yang, G. Y. Liu, and B. Chen, “Ecosystem health assessment and regulation for urban ecosystems: a case study of the yangtze river delta urban cluster, China," Journal of Environmental Informatics, vol. 18, no. 2, pp. 65-74, 2011.

[14] C. Zheng, W. Yang, and Z. F. Yang, "Strategies for managing environmental flows based on the spatial distribution of water quality: a case study of Baiyangdian Lake, China," Journal of Environmental Informatics, vol. 18, no. 2, pp. 84-90, 2011.

[15] L. Jing and B. Chen, "Field investigation and hydrological modelling of a subarctic wetland-the Deer River watershed," Journal of Environmental Informatics, vol. 17, no. 1, pp. 36-45, 2011.

[16] M. C. Acreman and A. J. D. Ferguson, "Environmental flows and the European Water Framework Directive," Freshwater Biology, vol. 55, no. 1, pp. 32-48, 2010.

[17] B. D. Richter, "A method for assessing hydrologic alteration within ecosystems," Conservation Biology, vol. 10, no. 4, pp. 1163-1174, 1996.

[18] B. D. Richter, J. V. Baumgartner, R. Wigington, and D. P. Braun, "How much water does a river need?" Freshwater Biology, vol. 37, no. 1, pp. 231-249, 1997.

[19] M. J. Kennard, B. J. Pusey, J. D. Olden, S. J. MacKay, J. L. Stein, and N. Marsh, “Classification of natural flow regimes in Australia to support environmental flow management," Freshwater Biology, vol. 55, no. 1, pp. 171-193, 2010.

[20] D. L. Tennant, "Instream flow regimens for fish, wildlife, recreation and related environmental resources," Fisheries, vol. 1, no. 4, pp. 6-10, 1976.

[21] K. D. Bovee, B. L. Lamb, J. M. Bartholow, C. B. Stalnaker, J. G. Taylor, and J. Henriksen, Stream Habitat Analysis Using the Instream Flow Incremental Methodology, US. Fish and Wildlife Service, 1998.

[22] N. L. Poff, B. D. Richter, A. H. Arthington et al., "The ecological limits of hydrologic alteration (ELOHA): a new framework for developing regional environmental flow standards," Freshwater Biology, vol. 55, no. 1, pp. 147-170, 2010.

[23] O. T. Gorman and J. R. Karr, "Habitat structure and stream fish communities," Ecology, vol. 59, pp. 507-515, 1978.

[24] N. L. Poff and J. V. Ward, "Physical habitat template of lotic systems: recovery in the context of historical pattern of spatiotemporal heterogeneity," Environmental Management, vol. 14, no. 5, pp. 629_ $646,1990$.

[25] D. A. Lytle and N. L. Poff, "Adaptation to natural flow regimes," Trends in Ecology and Evolution, vol. 19, no. 2, pp. 94-100, 2004.

[26] A. H. Arthington, S. E. Bunn, N. L. Poff, and R. J. Naiman, “The challenge of providing environmental flow rules to sustain river ecosystems," Ecological Applications, vol. 16, no. 4, pp. 1311-1318, 2006.

[27] N. L. Poff and J. K. H. Zimmerman, "Ecological responses to altered flow regimes: a literature review to inform the science and management of environmental flows," Freshwater Biology, vol. 55, no. 1, pp. 194-205, 2010.

[28] S. Postel and B. Richter, Rivers for Life: Managing Water for People and Nature, Island Press, Washington, DC, USA, 2003.

[29] A. F. Casper, B. Dixon, J. Earls, and J. A. Gore, "Linking a spatially explicit watershed model (SWAT) with an in-stream fish habitat model (PHABSIM): a case study of setting minimum flows and levels in a low gradient, sub-tropical river," River Research and Applications, vol. 27, no. 3, pp. 269-282, 2011.

[30] J. T. Shiau and F. C. Wu, "Feasible diversion and instream flow release using range of variability approach," Journal of Water Resources Planning and Management, vol. 130, no. 5, pp. 395-404, 2004.

[31] J. T. Shiau and F. C. Wu, "Compromise programming methodology for determining instream flow under multiobjective water allocation criteria," Journal of the American Water Resources Association, vol. 42, no. 5, pp. 1179-1191, 2006.

[32] J. W. Labadie, "Optimal operation of multireservoir systems: state-of-the-art review," Journal of Water Resources Planning and Management, vol. 130, no. 2, pp. 93-111, 2004.

[33] N. K. Ajami, G. M. Hornberger, and D. L. Sunding, "Sustainable water resource management under hydrological uncertainty," Water Resources Research, vol. 44, no. 11, Article ID W11406, 2008. 
[34] Y. P. Li and G. H. Huang, "Fuzzy-stochastic-based violation analysis method for planning water resources management systems with uncertain information," Information Sciences, vol. 179, no. 24, pp. 4261-4276, 2009.

[35] Y. P. Li, G. H. Huang, Y. F. Huang, and H. D. Zhou, "A multistage fuzzy-stochastic programming model for supporting sustainable water-resources allocation and management," Environmental Modelling and Software, vol. 24, no. 7, pp. 786-797, 2009.

[36] Y. P. Li, G. H. Huang, and S. L. Nie, "Planning water resources management systems using a fuzzyboundary interval-stochastic programming method," Advances in Water Resources, vol. 33, no. 9, pp. 1105-1117, 2010.

[37] Y. P. Li and G. H. Huang, "Inexact joint-probabilistic stochastic programming for water resources management under uncertainty," Engineering Optimization, vol. 42, no. 11, pp. 1023-1037, 2010.

[38] Y. P. Li, G. H. Huang, S. L. Nie, and X. Chen, "A robust modeling approach for regional water management under multiple uncertainties," Agricultural Water Management, vol. 98, no. 10, pp. 15771588, 2011.

[39] M. Q. Suo, Y. P. Li, and G. H. Huang, “An inventory-theory-based interval-parameter two-stage stochastic programming model for water resources management," Engineering Optimization, vol. 43, no. 9, pp. 999-1018, 2011.

[40] Y. O. Kim, H. I. Eum, E. G. Lee, and I. H. Ko, “Optimizing operational policies of a Korean multireservoir system using sampling stochastic dynamic programming with ensemble streamflow prediction," Journal of Water Resources Planning and Management, vol. 133, no. 1, pp. 4-14, 2007.

[41] M. J. Kennard, S. J. Mackay, B. J. Pusey, J. D. Olden, and N. Marsh, "Quantifying uncertainty in estimation of hydrologic metrics for ecohydrological studies," River Research and Applications, vol. 26, no. 2, pp. 137-156, 2010.

[42] J. T. Shiau and F. C. Wu, "A histogram matching approach for assessment of flow regime alteration: application to environmental flow optimization," River Research and Applications, vol. 24, no. 7, pp. 914-928, 2008.

[43] H. Liu, C. Jiang, and Y. Zhang, "Portfolio management of hydropower producer via stochastic programming," Energy Conversion and Management, vol. 50, no. 10, pp. 2593-2599, 2009.

[44] K. Høyland and S. W. Wallace, "Generating scenario trees for multistage decision problems," Management Science, vol. 47, no. 2, pp. 295-307, 2001.

[45] D. W. Watkins Jr., D. C. McKinney, L. S. Lasdon, S. S. Nielsen, and Q. W. Martind, “A scenario-based stochastic programming model for water supplies from the highland lakes," International Transactions in Operational Research, vol. 7, no. 3, pp. 211-230, 2000.

[46] S. Wang and G. H. Huang, "Identifying optimal water resources allocation strategies through an interactive multi-stage stochastic fuzzy programming approach," Water Resources Management, vol. 26, no. 7, pp. 2015-2038, 2012.

[47] J. Dupačová, G. Consigli, and S. W. Wallace, "Scenarios for multistage stochastic programs," Annals of Operations Research, vol. 100, pp. 25-53, 2000.

[48] H. Brand, E. Thorin, and C. Weber, "Scenario reduction algorithm and creation of multi-stage scenario trees," Optimization of Cogeneration Systems in a Competitive Market Environment, Discussion Paper no. 7, 2002.

[49] B. D. Richter, J. V. Baumgartner, D. P. Braun, and J. Powell, "A spatial assessment of hydrologic alteration within a river network," River Research and Applications, vol. 14, no. 4, pp. 329-340, 1998.

[50] J. T. Shiau and F. C. Wu, "Assessment of hydrologic alterations caused by chi-chi diversion weir in Chou-Shui Creek, Taiwan: opportunities for restoring natural flow conditions," River Research and Applications, vol. 20, no. 4, pp. 401-412, 2004.

[51] J. T. Shiau and F. C. Wu, "Pareto-optimal solutions for environmental flow schemes incorporating the intra-annual and interannual variability of the natural flow regime," Water Resources Research, vol. 43, no. 6, Article ID W06433, 2007.

[52] O. Marinoni, A. Higgins, S. Hajkowicz, and K. Collins, "The multiple criteria analysis tool (MCAT): a new software tool to support environmental investment decision making," Environmental Modelling and Software, vol. 24, no. 2, pp. 153-164, 2009.

[53] P. Fattahi and S. Fayyaz, "A compromise programming model to integrated urban water management," Water Resources Management, vol. 24, no. 6, pp. 1211-1227, 2010.

[54] G. E. Petts, Impounded Rivers: Perspectives for Ecological Management, Environmental Monographs and Symposia Series, John Wiley and Sons, Chichester, UK, 1984. 


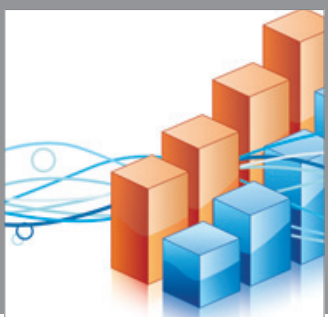

Advances in

Operations Research

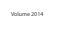

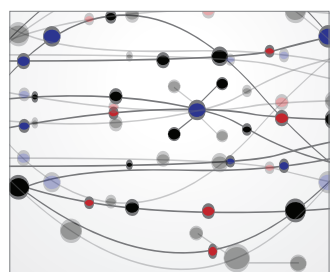

\section{The Scientific} World Journal
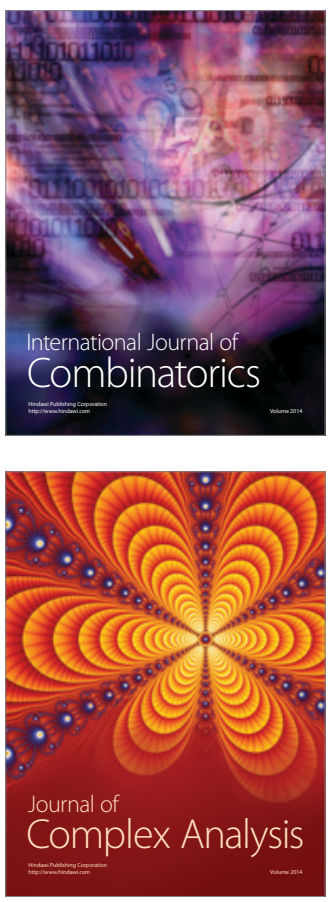

International Journal of

Mathematics and

Mathematical

Sciences
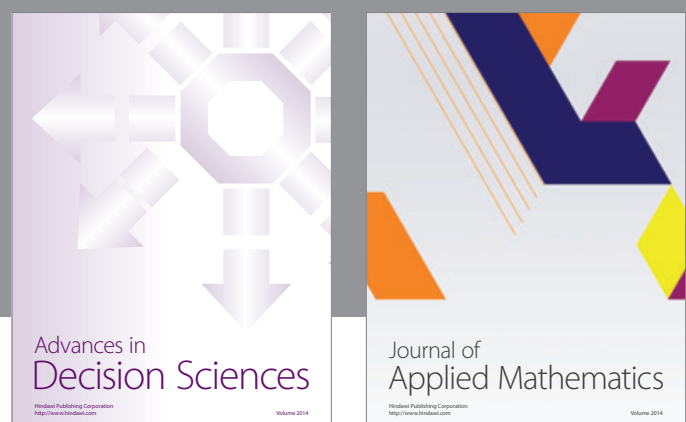

Journal of

Applied Mathematics
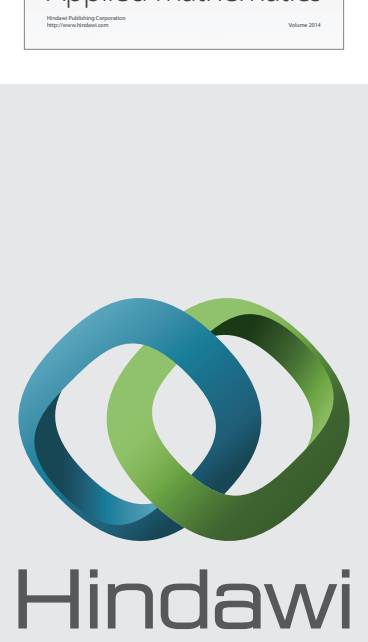

Submit your manuscripts at http://www.hindawi.com
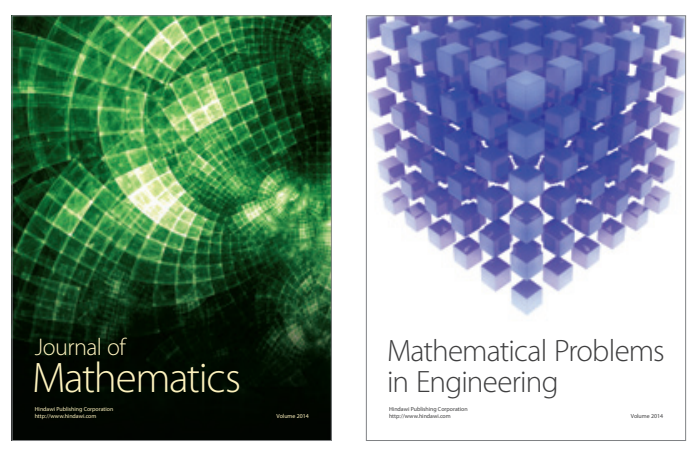

Mathematical Problems in Engineering
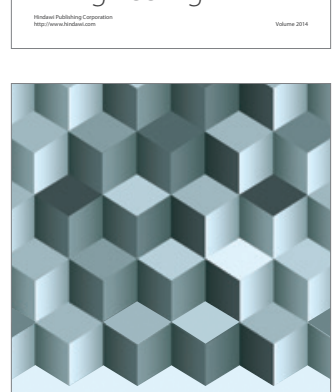

Journal of

Function Spaces
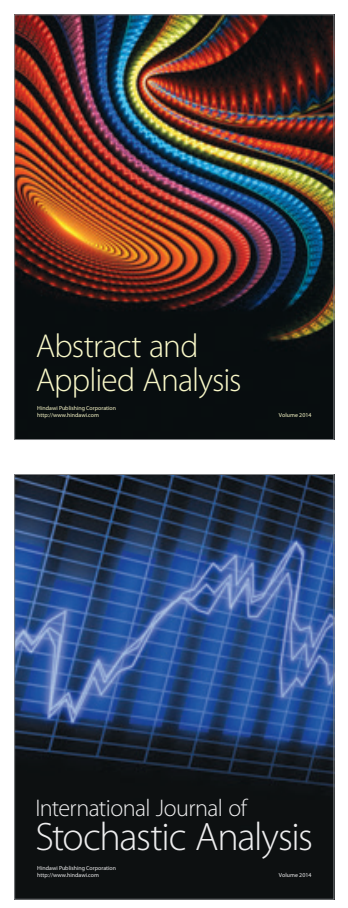

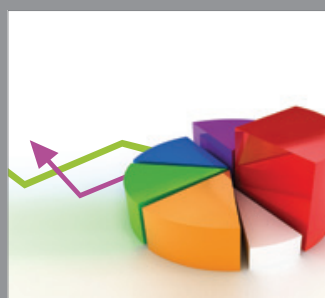

ournal of

Probability and Statistics

Promensencen
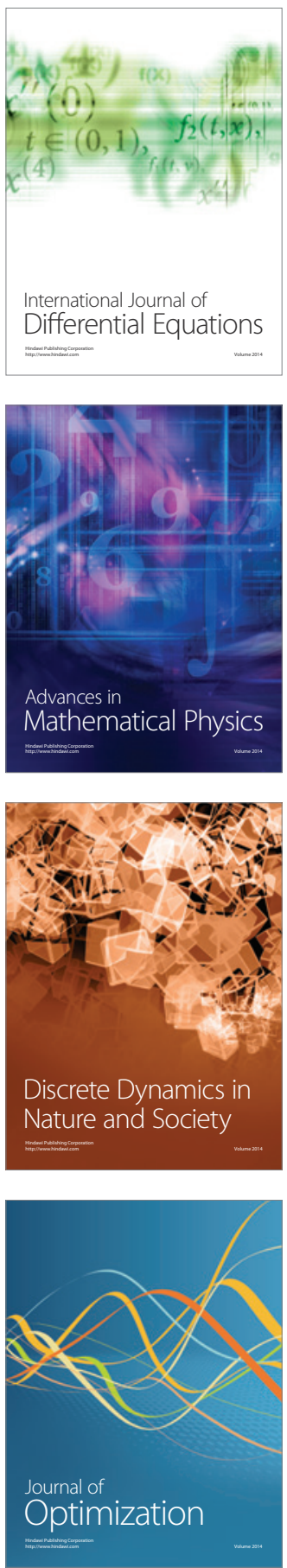